\title{
Size-specific locomotion rate and movement pattern of four common Indo-Pacific sea stars (Echinodermata; Asteroidea)
}

\author{
Benjamin Mueller ${ }^{1,2,4, *}$, Arthur R. $\operatorname{Bos}^{2,3}$, Gerhard Graf ${ }^{1}$, Girley S. Gumanao ${ }^{2}$ \\ ${ }^{1}$ Marine Biology Department, Bioscience, University of Rostock, Albert-Einstein-Straße 3, 18059 Rostock, Germany \\ ${ }^{2}$ Research Office, Davao del Norte State College, New Visayas, 8105 Panabo City, The Philippines \\ ${ }^{3}$ Department of Marine Zoology, Netherlands Center for Biodiversity Naturalis, PO Box 9517, 2300 RA Leiden, The Netherlands \\ ${ }^{4}$ Present address: Royal Netherlands Institute for Sea Research, PO Box 59, 1790 AB Den Burg, The Netherlands
}

\begin{abstract}
The ecology of sea stars appears to be related to their locomotive abilities. This relationship was studied for the sea stars Acanthaster planci, Archaster typicus, Linckia laevigata, and Protoreaster nodosus in the coastal waters of Samal Island, the Philippines between May and July 2008. In order to avoid the sensory interruptions that sea stars exhibit when moving across natural substrate, a tarpaulin $(2 \times 2 \mathrm{~m})$ was placed on the seafloor to create a uniform habitat. Mean $( \pm \mathrm{SD})$ locomotion rate of Archaster typicus was $45.8 \pm 17.0 \mathrm{~cm} \mathrm{~min}^{-1}$ but increased with mean radius $(R)$. Locomotion rate increased from 17.8 to $72.2 \mathrm{~cm} \mathrm{~min}^{-1}$ for specimens with $R$ of 1 and $5 \mathrm{~cm}$ respectively. Mean locomotion rate of L. laevigata, P. nodosus, and Acanthaster planci was 8.1 $\pm 1.9,18.8 \pm 3.9$, and $35.3 \pm 10.0 \mathrm{~cm} \mathrm{~min}^{-1}$ respectively, and was not related to $R$. Maximum speed of Archaster typicus was $76.0 \pm 31.9 \mathrm{~cm} \mathrm{~min}^{-1}$ and also increased with $R$. Maximum speed of L. laevigata, P. nodosus, and Acanthaster planci was $10.6 \pm 2.7,27.7 \pm 7.5$, and $50.9 \pm 14.0 \mathrm{~cm} \mathrm{~min}^{-1}$ respectively. An inter-specific comparison of locomotion rates using the number of body moves per minute suggests that the effect of body size partially overrules morphological and behavioral adaptations. The movement patterns of Acanthaster planci, L. laevigata, and P. nodosus were highly directional (ratio of displacement to total distance traveled $\left.\left[D: W_{\mathrm{all}}\right] \geq 0.86\right)$, whereas Archaster typicus displayed a more random movement pattern $\left(D: W_{\text {all }}=0.51\right)$. Water-current direction did not affect movement directions of the 4 species.
\end{abstract}

KEY WORDS: Acanthaster planci $\cdot$ Archaster typicus $\cdot$ Davao Gulf $\cdot$ Linckia laevigata $\cdot$ Protoreaster nodosus $\cdot$ Starfish $\cdot$ Speed

\section{INTRODUCTION}

The ability to migrate and the speed of migration has multiple implications for the biology and ecology of an animal (e.g. Hedenström 2003, Dingle \& Drake 2007). Benthic reef organisms such as sea stars, that move relatively slowly, may have to spend their entire life at the reef where they once settled. This implies that such organisms will reproduce in this spatial area and that a pelagic larval phase provides the only opportunity for long-distance dispersal (Williams \& Benzie 1993). Despite being relatively slow-moving animals, most Indo-Pacific sea stars have comparatively large distrib- ution areas. The larval periods of the Indo-Pacific sea stars Acanthaster planci (Linnaeus 1758) (Moran 1988), Linckia laevigata (Linnaeus 1758) (Williams \& Benzie 1993), and Protoreaster nodosus (Linnaeus 1758) (Bos et al. 2008a) are approximately 3 to $4 \mathrm{wk}$ and provide the potential for long-distance dispersal.

Sea stars move intermittently to search for food or to avoid physical stress (Feder \& Christensen 1966). For example, Archaster typicus (Müller et Troschel 1840) and Acanthaster planci may display locomotion rates of 15.1 to $24.9 \mathrm{~cm} \mathrm{~min}^{-1}$ (Run et al. 1988) and $33.3 \mathrm{~cm}$ $\mathrm{min}^{-1}$ (Moran 1990) respectively. Maximum speed in sea stars was assumed to be based on the positive rela- 
tionship between body size, and number (Gaymer \& Himmelman 2008) and length of tube feet (e.g. Westheide \& Rieger 1996). Hence, larger specimens move faster than smaller ones, both inter-specifically and intra-specifically. Maximum speed may also be a measure of the ability to avoid predation, e.g. for Archaster typicus. This sea star inhabits similar habitats as the larger omnivorous species Protoreaster nodosus, but does not share habitats with the latter. While Archaster typicus inhabits intertidal habitats such as sandy shores and seagrass meadows, juvenile $P$. nodosus are exclusively found in the adjacent shallow subtidal sand and seagrass areas (Bos et al. 2008a,b). This could be an indication that Archaster typicus avoids predation by P. nodosus (Bos et al. 2011). In contrast, the 2 species occurring in shallow soft-bottom habitats, Linckia laevigata and the multi-rayed corallivore sea star Acanthaster planci, are commonly encountered from the intertidal up to a depth of $60 \mathrm{~m}$ (Moran 1990, Schoppe 2000).

Locomotion rates and movement patterns of sea stars have been determined by marking tracks of individuals on natural substrates (e.g. Ferlin 1973, Scheibling 1981, Himmelman et al. 2005). However, limited observation time results in poor resolutions in time and space. Recently developed techniques such as timelapse video analysis (e.g. Dale 1997, Lauzon-Guay et al. 2006, Dumont et al. 2007, McClintock et al. 2008a,b) provide researchers with highly accurate data but require costly equipment. The use of an artificial substrate attached to the seafloor combines the advantage of observations under natural conditions and the avoidance of movement interruptions when sea stars encounter prey, which is likely to happen on natural substrates.

The present study aims to determine the size-specific locomotion rate and maximum speed and describe the movement patterns of 4 common Indo-Pacific sea stars: Acanthaster planci, Archaster typicus, Linckia laevigata, and Protoreaster nodosus.

\section{MATERIALS AND METHODS}

Sea star collection and measurements. Sea stars were collected in the coastal waters of Samal Island in the Davao Gulf, The Philippines from May to July 2008 (Acanthaster planci: 4 June to 2 July, Archaster typicus: 5 to 20 May, Linckia laevigata: 11 to 26 June, and Protoreaster nodosus: 5 May to 2 July). Collection was usually done by means of snorkeling, whereas the collection of larger specimens of L. laevigata and Acanthaster planci was done using SCUBA equipment. Since sea stars cease movement after handling (Dale 1997), specimens were acclimated for 2 to $12 \mathrm{~h}$ in a submerged net-covered container $(45 \times 20 \times 30 \mathrm{~cm})$ to minimize handling stress.

Radius (distance from arm tip to center of oral disk) of each arm was measured with calipers (accuracy: $1 \mathrm{~mm}$ ) at the oral side to calculate mean radius $(R)$. In the case of Acanthaster planci, the diameter $(=2 R)$ was measured with a ruler (accuracy: $5 \mathrm{~mm}$ ) at the aboral side before collection, because this species curls itself when handled.

Specimens of Archaster typicus ( $R=1$ to $5 \mathrm{~cm}$ ) were categorized in nine $0.5 \mathrm{~cm}$ size classes. Specimens of the other 3 species were categorized in $1 \mathrm{~cm}$ size classes, due to their larger sizes (Acanthaster planci: $R=4$ to $19 \mathrm{~cm}$, Linckia laevigata: $R=4$ to $15 \mathrm{~cm}$, Protoreaster nodosus: $R=2$ to $14 \mathrm{~cm}$ ).

Experimental design and observations. A tarpaulin $(2 \times 2 \mathrm{~m})$ with a printed grid $(10 \times 10 \mathrm{~cm}$ squares $)$ was laid on the surface of the substratum. Squares were vertically lettered and horizontally numbered (Fig. 1). The tarpaulin, weighted with a metal chain along its entire circumference, was firmly attached to the sea floor with pegs in an intertidal sandy area (grid always facing north). Observations were performed in water with depth ranging from 0.3 to $2.0 \mathrm{~m}$ while we snorkeled above the tarpaulin.

Each sea star was carefully positioned in the center of the tarpaulin always with its madreporite to the south. This orientation was not possible for Acanthaster planci, which is a multi-madreporite species. As soon as a sea star started moving, we started a stopwatch (accuracy: $1 \mathrm{~s}$ ). Time and square label were recorded each time an individual reached another square of the grid. An observation was terminated when a sea star reached the edge of the tarpaulin or after performing a traveling path of $>20$ squares. Slow movement of Linckia laevigata made it necessary for us to terminate observations after measuring 10 consecutive squares. Due to difficulties in recording the exact traveling path on a slate, an observation was also terminated when a sea star visited a particular square a third time.

The following environmental parameters were recorded before each observation: (1) water depth (estimated in $5 \mathrm{~cm}$ intervals), (2) bottom water temperature $\left(0.5^{\circ} \mathrm{C}\right.$ accuracy $),(3)$ wave activity $(0=$ no waves, $1=$ small waves, 2 = medium waves, $3=$ choppy), (4) water current speed (measured with float and stopwatch in $\mathrm{cm} \mathrm{s}^{-1}$ ), and (5) water current direction (Table 1).

Data analysis. Displacement of sea stars was calculated trigonometrically for each square of the tarpaulin. Sea star velocity was calculated by dividing the displacement $(D)$ by the time needed to move to a neighboring square. An observation started when a sea star began its traveling path in the center of the tarpaulin (starting point, S) and lasted until it left the tar- 

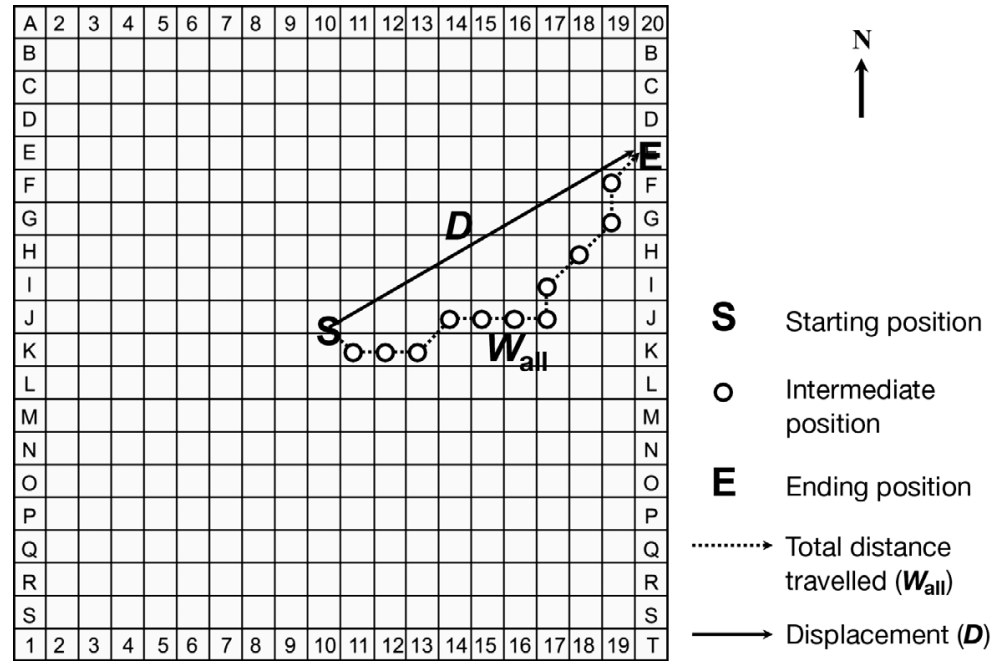

Fig. 1. Tarpaulin $(2 \times 2 \mathrm{~m})$ with printed grid $(10 \times 10 \mathrm{~cm}$ squares $)$. Schematic traveling path of one sea star explaining total distance traveled ( $\left.W_{\text {all }}\right)$ and displacement $(D)$

paulin (ending point, E) (Fig. 1). Therefore, one observation consisted of a number of consecutive sections. Locomotion rate was determined by calculating the mean speed of all sections within one observation, whereas maximum speed was the highest velocity.

Body moves per minute were calculated by dividing locomotion rate by the diameter $(2 R)$ for each specimen to study inter-specific locomotive differences independent of size. The pattern of movement was characterized as the ratio of $D$ to total distance traveled $(W)$ (Ferlin 1973 modified by Scheibling 1981). D is the shortest distance between $\mathrm{S}$ and $\mathrm{E}$, whereas $W_{\text {all }}$ is the total distance traveled by a specimen during one observation (Fig. 1). An individual moving in a straight line displays a directional movement pattern and has a $D: W_{\text {all }}$ of 1 . The more the actual movement path deviates from a straight line, the smaller $D: W_{\text {all }}$ and the less directed the movement pattern becomes. $D: W_{\text {all }}$ values $>0.7$ are considered to be highly directional, values $>0.5$ partially directional, whereas values $<0.5$ are considered to be undirected (Ferlin 1973, Scheibling 1981). $D: W_{5}$ was calculated by only considering the first 5 squares of the observations to test for size-dependent effects within the movement patterns.

Differences in mean locomotion rate, maximum speed, and $D: W_{\text {all }}$ and $D: W_{5}$ ratios were tested with 1-way ANOVA if homogeneity of variance was shown (Levene's test). In case of heterogeneity, a Welch ANOVA was used. Post hoc analysis was done with Tukey's HSD test.

The influence of water currents on the movement direction of sea stars was tested by calculating the deviation of the movement direction from the direction of the current. The Rayleigh test (Zar 1999) was used to determine whether the angles between movement direction and direction of the current were uniformly distributed around the $360^{\circ}$ circle (which is expected when there is no influence of currents on the movement direction).

\section{RESULTS}

Linckia laevigata's locomotion rate was the lowest, with a mean of $8.1 \mathrm{~cm} \mathrm{~min}{ }^{-1}$, while Protoreaster nodosus and Acanthaster planci moved at approximately double and 4 times that rate (Table 2). Archaster typicus was the fastest-moving sea star, with a mean locomotion rate of $45.8 \mathrm{~cm} \mathrm{~min}^{-1}$ (Table 2).

Archaster typicus' locomotion rate significantly increased with $R$ from 17.8 to $72.2 \mathrm{~cm} \mathrm{~min}^{-1}$ (Fig. 2). Similarly, a significant linear relationship was found between maximum speed and $R$ for $A$. typicus. There was no significant relationship between both mean and maximum locomotion rates and $R$ for the other 3 species (Fig. 2).

The number of body moves per minute was interspecifically related to $R$ (Fig. 3). Small specimens $(R<$ $2 \mathrm{~cm}$ ) performed 6 to 12 body moves $\min ^{-1}$, whereas specimens with $R>5 \mathrm{~cm}$ could only perform $<4$ body moves $\min ^{-1}$.

Table 1. Acanthaster planci, Archaster typicus, Linckia laevigata, and Protoreaster nodosus. Environmental parameters measured during observations. Wave action: $0=$ no waves, $1=$ small waves, $2=$ medium waves

\begin{tabular}{|lcccccc|}
\hline \multirow{2}{*}{ Species } & \multirow{2}{*}{ Depth $(\mathrm{cm})$} & \multicolumn{2}{c}{ Temperature $\left({ }^{\circ} \mathrm{C}\right)$} & \multicolumn{2}{c|}{ Current velocity $\left(\mathrm{cm} \mathrm{s}^{-1}\right)$} & \multirow{2}{*}{ Wave action } \\
& & Range & Mean \pm SD & Range & Mean \pm SD \\
\hline Acanthaster planci & $30-185$ & $29.5-31.0$ & $29.7 \pm 0.5$ & $0-6.3$ & $5.4 \pm 1.3$ & $1-2$ \\
Archaster typicus & $40-190$ & nd & nd & $0-11.7$ & $5.0 \pm 2.9$ & $0-2$ \\
Linckia laevigata & $65-170$ & $29.5-30.5$ & $29.7 \pm 0.5$ & $0-14.5$ & $7.8 \pm 4.5$ & $1-2$ \\
Protoreaster nodosus & $30-185$ & $29.5-32.0$ & $30.3 \pm 0.9$ & $0-8.9$ & $5.0 \pm 2.2$ & $1-2$ \\
\hline
\end{tabular}


Table 2. Acanthaster planci, Archaster typicus, Linckia laevigata, and Protoreaster nodosus. Locomotion rate, maximum speed, and the ratio of displacement $(D)$ to distance traveled $(W)$ for the full observation $\left(D: W_{\text {all }}\right)$ and for the first 5 squares $\left(D: W_{5}\right)$. Data are mean $\pm \mathrm{SD}$

\begin{tabular}{|lccccc|}
\hline Species & $\mathrm{n}$ & $\begin{array}{c}\text { Locomotion } \\
\text { rate }\left(\mathrm{cm} \mathrm{min}^{-1}\right)\end{array}$ & $\begin{array}{c}\text { Maximum speed } \\
\left(\mathrm{cm} \mathrm{min}^{-1}\right)\end{array}$ & $D: W_{\text {all }}$ & $D: W_{5}$ \\
\hline Acanthaster planci & 38 & $35.3 \pm 10.0$ & $50.9 \pm 14.0$ & $0.86 \pm 0.12$ & $0.93 \pm 0.13$ \\
Archaster typicus & 29 & $45.8 \pm 17.0$ & $76.0 \pm 31.9$ & $0.51 \pm 0.29$ & $0.68 \pm 0.19$ \\
Linckia laevigata & 29 & $8.1 \pm 1.9$ & $10.6 \pm 2.7$ & $0.88 \pm 0.13$ & $0.90 \pm 0.13$ \\
Protoreaster nodosus & 38 & $18.8 \pm 3.9$ & $27.7 \pm 7.5$ & $0.89 \pm 0.13$ & $0.88 \pm 0.13$ \\
\hline
\end{tabular}

The mean $D: W_{5}$ ratio of Acanthaster planci, Linckia laevigata, and Protoreaster nodosus ranged from 0.88 to 0.93 and for Archaster typicus it was 0.68 . Acanthaster planci's and Archaster typicus' mean $D: W_{5}$ ratio was significantly higher than their $D: W_{\text {all }}$ ratio (Tukey's test, $\mathrm{p}<0.05)$. No significant difference was found for the other 2 species (ANOVA, p > $0.05)$.

The mean $D: W_{\text {all }}$ ratio of Acanthaster planci, Linckia laevigata, and Protoreaster nodosus ranged from 0.86 to 0.89 (Table 2), whereas Archaster typicus' mean $D: W_{\text {all }}$ ratio of 0.51 was significantly lower (Tukey's test, $\mathrm{p}<0.05)$. No significant difference was found among the other 3 species (ANOVA, p > 0.05).

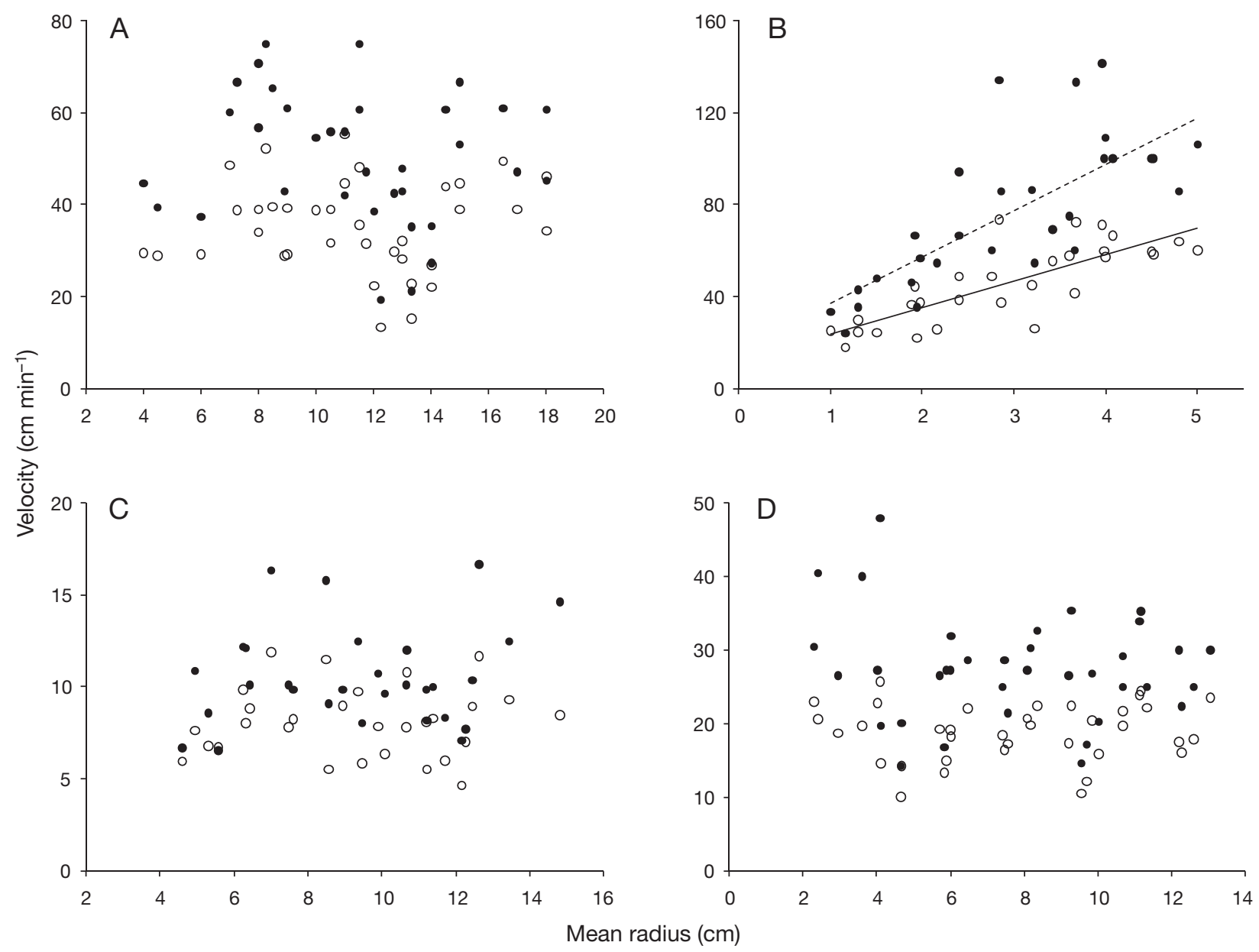

Fig. 2. (A) Acanthaster planci $(\mathrm{n}=38)$, (B) Archaster typicus $(\mathrm{n}=29),(\mathrm{C})$ Linckia laevigata $(\mathrm{n}=29)$, and (D) Protoreaster nodosus $(\mathrm{n}=38)$. Velocity as a function of mean radius $(R)$. Locomotion rate $(0)$ and maximum speed $(\bullet)$ are shown. Linear regression of locomotion rate $(-)\left(\mathrm{r}^{2}=0.633, \mathrm{p}<0.001, y=11.466 \times R+12.207\right)$ and of maximum speed $(---)\left(\mathrm{r}^{2}=0.548, \mathrm{p}<0.001, y=20.091\right.$ $\times R+17.102)$ for $A$. typicus are also shown. Note the differences in scale of the vertical axes 


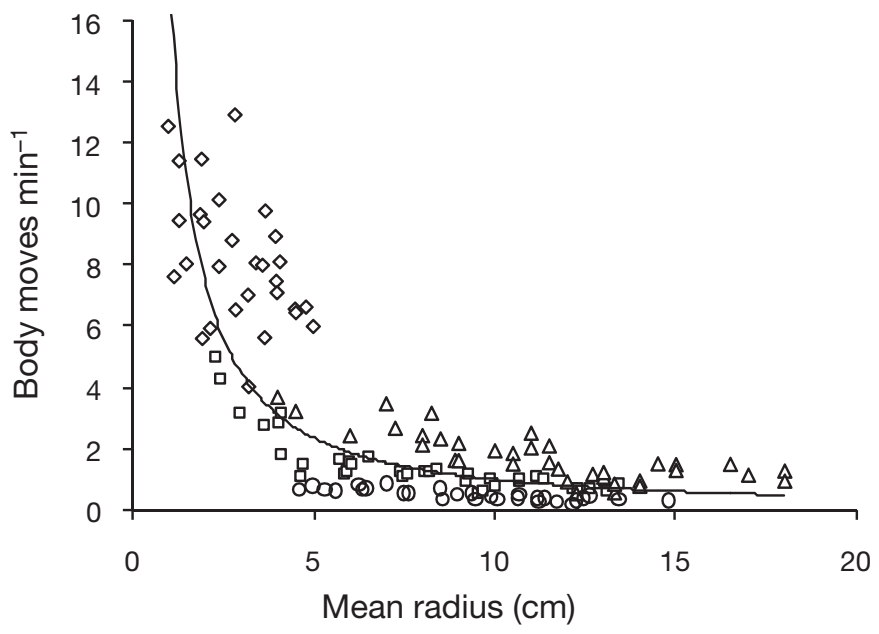

Fig. 3. Acanthaster planci $(\Delta, \mathrm{n}=38)$, Archaster typicus $(\diamond$, $\mathrm{n}=29)$, Linckia laevigata $(\mathrm{O}, \mathrm{n}=29)$, and Protoreaster nodosus $(\square, \mathrm{n}=38)$. Body moves per minute as function of mean radius $(R)$. Solid line represents best fit line for all 4 species $\left(\mathrm{r}^{2}=0.605, y=17.822 \times R^{-1.261}\right)$

\section{DISCUSSION}

Substrates may affect locomotion rates and movement pattern of sea stars. Ferlin (1973) reported that Astropecten aranciacus moved at higher velocities on fine sand than on coarse sand. In contrast, Scheibling (1981) found that the locomotion rate of Oreaster reticulatus did not vary between fine and coarse sand. Velocities measured on tarpaulin could therefore differ from values measured on natural substratum. However, the mean locomotion rate of Acanthaster planci of $35.3 \mathrm{~cm} \mathrm{~min}^{-1}$ (Table 2) closely resembles the rate of $33 \mathrm{~cm} \mathrm{~min}^{-1}$ on sand reported by Moran (1990). Therefore the use of a tarpaulin to compare inter- and intraspecific movement of sea stars seems to be a suitable in-field method, even if results must be extrapolated to the natural environment with some caution.

Movement patterns of animals are an integrated component of their feeding strategy. Pyke et al. (1977) stated in the optimal foraging theory that natural selec-
Fig. 4. (A) Acanthaster planci $(\mathrm{n}=30)$, (B) Archaster typicus $(\mathrm{n}=21)$, (C) Linckia laevigata (n = 22), and (D) Protoreaster nodosus $(\mathrm{n}=33)$. Deviation of the movement direction from the water current direction. Arrows indicate the water current direction $\left(0^{\circ}\right)$. Distance from the center of the plot represents displacement $(D)$. Horizontal numbered lines indicate distance in $\mathrm{cm}$. The $p$-values of the Rayleigh test are shown

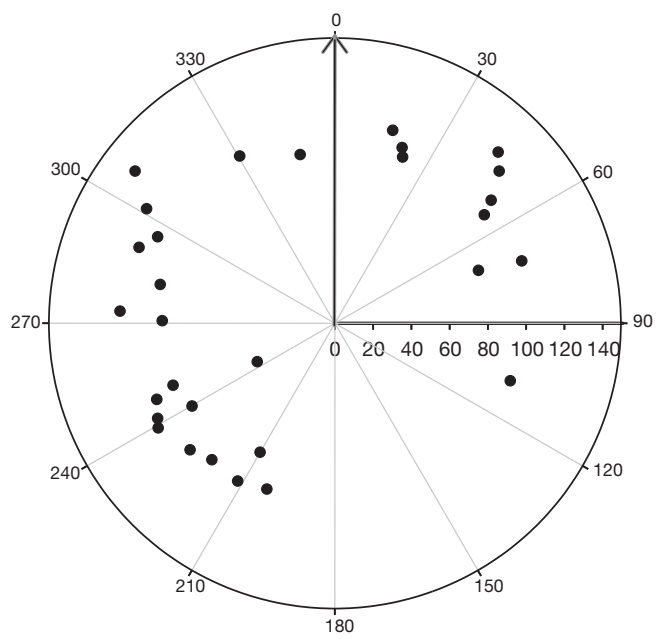

A

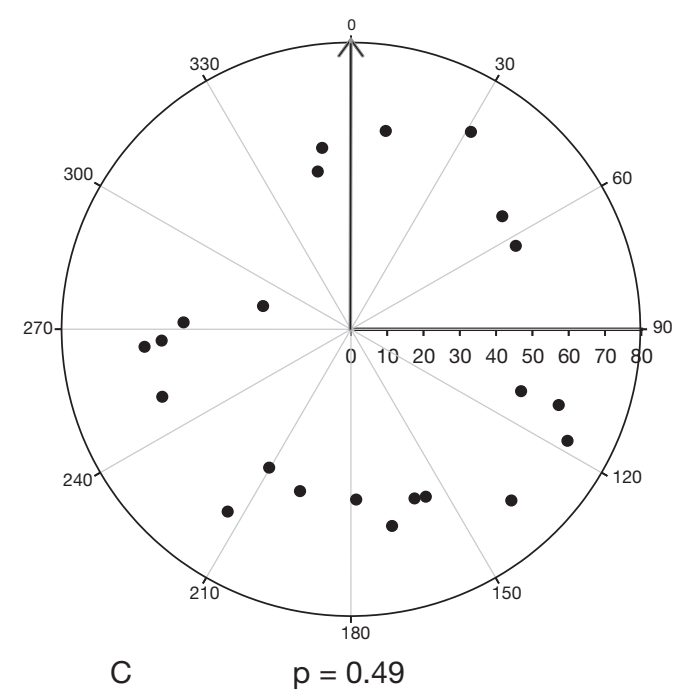

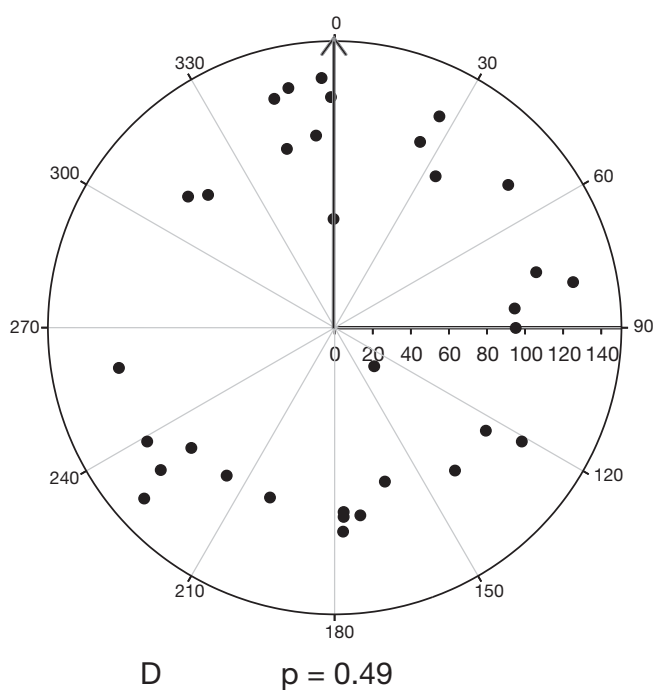

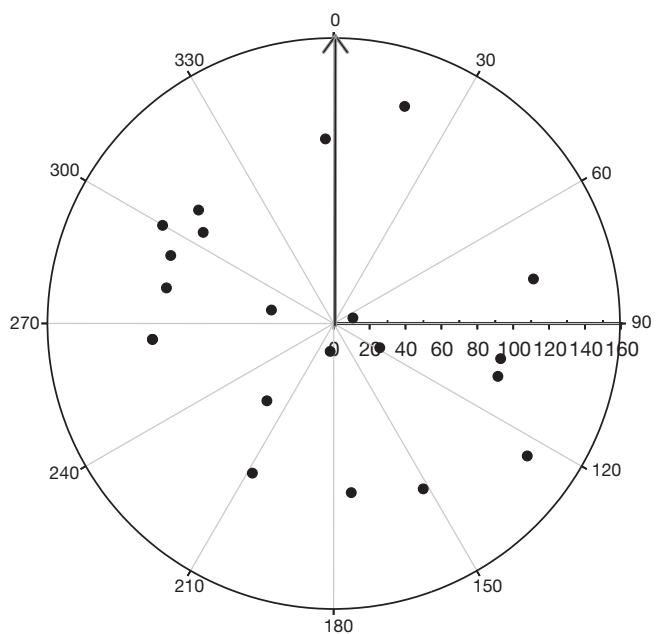

B

$\mathrm{p}=0.12$

$p=0.49$ 
tion may optimize movement patterns in relation to distribution and abundance of prey over evolutionary times. The goal of optimal foraging is to maximize the net rate of food uptake (Pyke et al. 1977, Krebs 1978). A highly directional movement pattern, as earlier described for sea stars (Scheibling 1981), optimizes foraging efficiency on substrata containing a relatively uniform distribution of food resources because it prevents re-grazing of substrata and extends the foraging range (Scheibling 1981). This seems to be the case for Acanthaster planci, Linckia laevigata, and Protoreaster nodosus, which all had a $D: W_{\text {all }}$ of approximately 0.9 . Their movement was highly directional, whereas the movement path of Archaster typicus showed a partially directional pattern, with a $D: W_{\text {all }}$ of about 0.5 .

Inter-specific interactions have the potential to determine sea-star foraging behavior under natural conditions (Himmelman \& Dutil 1991, Morissette \& Himmelman 2000, Gaymer et al. 2002, Gaymer \& Himmelman 2008). In the present experiment, however, these were excluded because specimens were placed on the tarpaulin one at a time.

Beddingfield \& McClintock (1993) found that Astropecten articulatus exhibited a directional pattern of movement in the absence of food. When encountering prey, however, both the frequency and magnitude of angular deviations in the foraging path increased, resulting in intensified foraging in areas with high prey density. This seems to be a highly efficient foraging strategy that may be used by many organisms. Generally, undirected movement patterns may be an adaptation to living in high density in an environment with locally high prey density (McClintock \& Lawrence 1985). This may be the case for Archaster typicus, which has densities of up to 131 ind. $\mathrm{m}^{-2}$ (Bos et al. 2011) in the prey-abundant intertidal zone.

The relative small body size of Archaster typicus (up to $15 \mathrm{~cm}$ in diameter; Janssen et al. 1984) compared to the size of the other 3 sea stars in the present study may also explain the more undirected pattern of movement of this species. Sea stars may generally show directed movement for a certain distance that is related to their body size before changing their movement direction. Consequently, small sea stars would move a shorter distance before changing direction than larger ones. In fact, when just considering the first 5 squares of our observation ( $\left.D: W_{5}\right)$, Archaster typicus' movement path was more directed. This was also the case for Acanthaster planci, which is much larger than Archaster typicus. In contrast, Linckia laevigata's and Protoreaster nodosus' $D: W_{5}$ ratios do not differ significantly from their $D: W_{\text {all }}$ ratios, although they are about the same size as Acanthaster planci. Furthermore, when comparing the $D: W$ ratio throughout all size classes of Archaster typicus or within the other 3 spe- cies, there is no evidence for a size-dependent relationship between pattern of movement and body size.

Water currents are used by numerous mobile marine organisms for orientation and to detect food. Sea stars have been variously reported to move upstream (e.g. Castilla \& Crisp 1973) or cross-stream, which increases the chance of detecting waterborne chemical stimuli (Rochette et al. 1994). In our experiments, all 4 sea star species did not show a preferential angle of movement in relation to the water current direction. This suggests that the use of a tarpaulin as substrate worked well in avoiding sensory interruptions.

Large sea stars are thought to move faster than smaller specimens (e.g. Westheide \& Rieger 1996), based on the assumption that velocity depends on the number (Gaymer \& Himmelman 2008) and length of tube feet and thus on body size (Westheide \& Rieger 1996). Indeed, Moran (1990) reported that small Acanthaster planci were slower than large specimens. However, Ferlin (1973) found body size and velocity of the sea star Astropecten aranciacus not to be related. In the present study, we found a significant linear relationship between $R$ and both locomotion rate and maximum speed for Archaster typicus, which confirms that larger sea stars move faster than smaller ones. However, although Archaster typicus displayed the highest locomotion rate, it was the smallest species studied. A relationship between body size and velocity was not found for the other 3 species though. Hence, the relationship between body size and velocity of sea stars may just be species-specific. Nevertheless, morphological differences may explain inter-specific variation in locomotion rate. Blake (1989) hypothesized that seastar growth either stresses strength and sturdiness or flexibility. The relatively small, thickened disk and the moderately enlarged marginal plates of Linckia laevegata and Protoreaster nodosus provide sturdiness and protection, whereas the relatively larger and flattened disk as well as the less-developed marginal plates of Acanthaster planci and Archaster typicus feature flexibility, which promotes locomotive activity. This supports our findings that Acanthaster planci and Archaster typicus perform higher locomotion rates than L. laevigata and P. nodosus. Moreover, Acanthaster planci is a multi-armed sea star with a large disk and relatively high number of tube feet and therefore presumably has increased predatory abilities such as locomotion (Blake 1989). Furthermore, tube-foot morphology is likely to affect locomotion rates. Santos et al. (2005) hypothesized that tube-foot morphology is influenced by the adaption to habitats and varying substrate types (Blake 1990) but within limits imposed by the evolutionary lineage (Vickery \& McClintock 2000). In accordance to this theory, all 4 species in the present study feature the typical valvatid simple disk- 
ending type of tube foot, but with minor modifications (Santos et al. 2005). Acanthaster planci and L. laevigata are usually encountered in highly structured, 3-dimensional hard-substrate habitats and so the main functions of their tube feet are locomotion and fixation (Santos et al. 2005). In contrast, Archaster typicus and $P$. nodosus both occur in less-structured soft-bottom habitats and the main function of their tube feet is primarily locomotion. Therefore, it would be likely that the latter 2 species have higher locomotion rates than the 2 species that are adapted to highly structured environments, especially under our experimental conditions on a 2-dimensional tarpaulin. And in fact, $L$. laevigata showed the lowest locomotion rate of all 4 species tested. However, Acanthaster planci had the second highest locomotion rate. A possible explanation might be that its relatively fast locomotion rate may allow Acanthaster planci to move over sandy areas in search of coral prey and may provide it with the potential to migrate from one reef to another (Moran 1988). This could also explain the successful spreading over large coral reef areas during outbreaks of Acanthaster planci (e.g. Moran 1986, Babcock et al. 1994, Bos 2010).

Other explanations for variation in inter-specific locomotion rates may be given by differences in prey abundance, prey quality, and feeding behavior. Linckia laevigata is known to be a microphagous feeder grazing on detritus and small invertebrates living in algal mats (Schoppe 2000). For this species, there seems to be no need to move fast, because its prey does not move (or only slowly) and is usually abundant. Protoreaster nodosus on the other hand is an opportunistic microphagous feeder (Schoppe 2000), also feeding on mobile invertebrates such as heart urchins (Bos et al. 2008a). While foraging, P. nodosus often covers longer distances (B. Mueller et al. pers. obs.), which makes it beneficial to move at a considerable speed. Acanthaster planci, a coralivore, may need to migrate to other feeding grounds when food becomes scarce, which may occur during population outbreaks. Moreover, large numbers of $A$. planci were observed to move from deeper water up the slopes of reefs during early stages of outbreaks (Moran 1988). Moran (1988) suggested that larvae had settled at the base of the reefs about 2 yr earlier and spent their juvenile life stages there feeding on coralline algae. When maturing, feeding behavior changes and sub-adults migrate to shallower reefs to prey on coral polyps.

One further reason to explain inter-specific differences in locomotion rate may be the existence of migration as part of a species' life cycle. Bos et al. (2008a) found juvenile Protoreaster nodosus $(R<$ $8.0 \mathrm{~cm}$ ) exclusively in shallow sandy habitats with abundant seagrass in water $\leq 2 \mathrm{~m}$ deep, whereas adults $(R=10 \mathrm{~cm})$ were found at a water depth ranging from
0 to $37 \mathrm{~m}$ independent of seagrass presence. They suggested that juvenile $P$. nodosus displays a gradual migration to adult habitats, which would underline the biological need for a certain level of locomotion.

Our findings on the size-dependent locomotion rate of the 4 tested valvatid sea-star species suggest that there is a relationship between body size and locomotion rate, irrespective of species affiliation. Specimens of all 4 species moved at the same speed in relation to their body size. Hence, if this is the case, the body size of a specimen may partly overrule species-specific characteristics such as body structure and tube-foot morphology and therefore morphological and behavioral adaptations.

Acknowledgements. We thank M. Kochen, F. van Duyl, and 4 anonymous reviewers for comments on an earlier version of the manuscript and E. Meesters for providing statistical advice. Furthermore, we thank A. Rogers for fine-tuning the document's language. This study was performed and in part financed through cooperation between the German Development Service (DED) and the Davao del Norte State College. All experiments complied with the current laws of the Republic of the Philippines.

\section{LITERATURE CITED}

Babcock RC, Mundy CN, Whitehead D (1994) Sperm diffusion models and in situ confirmation of long-distance fertilization in the free-spawning asteroid Acanthaster planci. Biol Bull (Woods Hole) 186:17-28

Beddingfield SD, McClintock JB (1993) Feeding behavior of the sea star Astropecten articulatus (Echinodermata: Asteroidea): an evaluation of energy-efficient foraging in a soft-bottom predator. Mar Biol 115:669-676

Blake DB (1989) Asteroidea: functional morphology, classification and phylogeny. In: Jangoux M, Lawrence JM (eds) Echinoderm studies, Vol 3. Balkema, Rotterdam, p 179-223

Blake DB (1990) Adaptive zones of the class Asteroidea (Echinodermata). Bull Mar Sci 46:701-718

Bos AR (2010) Crown-of-thorns outbreak at the Tubbataha Reefs UNESCO World Heritage Site. Zool Stud 49:124

> Bos AR, Gumanao GS, Alipoyo JCE, Cardona LT (2008a) Population dynamics, reproduction and growth of the IndoPacific horned sea star, Protoreaster nodosus (Echinodermata; Asteroidea). Mar Biol 156:55-63

Bos AR, Alipoyo JCE, Cardona LT, Gumanao GS, Salac N (2008b) Population structure of common Indo-Pacific sea stars in the Davao Gulf. Philippine Association of Marine Science Proceedings. UPV J Nat Sci 13:11-24

Bos AR, Gumanao GS, van Katwijk MM, Mueller B, Saceda MM, Tejada RP (2011) Ontogenetic habitat shift, population growth and burrowing behavior of the Indo-Pacific beach star, Archaster typicus (Echinodermata; Asteroidea). Mar Biol 158:639-648

Castilla JC, Crisp DJ (1973) Responses of Asterias rubens to water currents and their modification by certain environmental factors. Neth J Sea Res 7:171-190

Dale J (1997) Chemosensory search behavior in the sea star Asterias forbesi. Biol Bull 193:210-212

> Dingle H, Drake VA (2007) What is migration? Bioscience 57:113-121 
Dumont CP, Himmelman JH, Robinson SMC (2007) Random movement pattern of the sea urchin Strongylocentrotus droebachiensis. J Exp Mar Biol Ecol 340:80-89

Feder HM, Christensen AM (1966) Aspects of asteroid biology. In: Boolootian RA (ed) Physiology of Echinodermata. Wiley, New York, NY, p 87-127

Ferlin V (1973) The mode of dislocation of Astropecten aranciacus. Helgol Wiss Meeresunters 24:151-156

Gaymer CF, Himmelman JH (2008) A keystone predatory sea star in the intertidal zone is controlled by a higher order sea star predator in the subtidal zone. Mar Ecol Prog Ser 370:143-153

Gaymer CF, Himmelman JH, Johnson LE (2002) Effect of intraand interspecific interactions on the feeding and behavior of two subtidal seastars in the northern Gulf of St. Lawrence, eastern Canada. Mar Ecol Prog Ser 232:149-162

Hedenström A (2003) Scaling migration speed in animals that run, swim and fly. J Zool (Lond) 259:155-166

Himmelman JH, Dutil C (1991) Distribution, population structure and feeding of subtidal seastars in the northern Gulf of St. Lawrence. Mar Ecol Prog Ser 76:61-72

- Himmelman JH, Dutil C, Gaymer CF (2005) Foraging behavior and activity budgets of sea stars on a subtidal sediment bottom community. J Exp Mar Biol Ecol 322:153-165

Janssen HH, Orosco C, Largo D, Ayson F, Uy W (1984) Some recent findings on the sea star, Archaster typicus Mueller and Troschel 1840. Philipp Sci 21:51-74

Krebs JR (1978) Optimal foraging: decision rules for predators. In: Krebs JR, Davies NB (eds) Behavioral ecology. Sinauer Associates, Sunderland, MA, p 23-63

Lauzon-Guay JS, Scheibling RE, Barbeau MA (2006) Movement patterns in the green sea urchin, Strongylocentrotus droebachiensis. J Mar Biol Assoc UK 86:167-174

McClintock JB, Lawrence JM (1985) Characteristics of foraging in the soft-bottom benthic starfish Luidia clathrata (Echinodermata: Asteroidea): prey selectivity, switch behavior, functional responses and movement patterns. Oecologia 66:291-298

McClintock JB, Angus RA, Ho C, Amsler CD, Baker BJ (2008a) A laboratory study of behavioral interactions of the Antarctic keystone sea star Odontaster validus with three sympatric predatory sea stars. Mar Biol 154: 1077-1084

McClintock JB, Ho C, Angus RA, Amsler CD (2008b) Inter-

Editorial responsibility: Hans Heinrich Janssen,

Oldendorf/Luhe, Germany specific agonistic arm-fencing behavior in the Antarctic keystone sea star Odontaster validus. Mar Ecol Prog Ser 371:297-300

Moran PJ (1986) The Acanthaster phenomenon. Oceanogr Mar Biol Annu Rev 24:379-480

Moran PJ (1988) Crown-of-thorns sea star: questions and answers. Australian Institute of Marine Science, Townsville

Moran PJ (1990) Acanthaster planci (L): biographical data. Coral Reefs 9:95-96

Morissette S, Himmelman JH (2000) Decision of the asteroid Leptasterias polaris to abandon its prey when confronted with its predator, the asteroid Asterias vulgaris. J Exp Mar Biol Ecol 252:151-157

Pyke G, Pullian HE, Charnov E (1977) Optimal foraging: a selective review of theories and tests. Q Rev Biol 52: $137-154$

> Rochette R, Hamel JF, Himmelman JH (1994) Foraging strategy of the asteroid Leptasterias polaris: role of prey odors, current and feeding status. Mar Ecol Prog Ser 106:93-100

Run JQ, Chen CP, Chang KH, Chia FS (1988) Mating behaviour and reproductive cycle of Archaster typicus (Echinodermata: Asteroidea). Mar Biol 99:247-253

Santos R, Haesaertes D, Jangoux M, Flammang P (2005) Comparative histological and immunohistochemical study of sea star tube feed (Echinodermata, Asteroidea). J Morphol 263:259-269

Scheibling RE (1981) Optimal foraging movements of Oreaster reticulatus (L) (Echinodermata: Asteroidea). J Exp Mar Biol Ecol 51:173-185

Schoppe S (2000) Echinoderms of the Philippines. Times Edition, Singapore

Vickery MS, McClintock JB (2000) Comparative morphology of tube feet among the Asteroidea: phylogenetic implications. Am Zool 40:355-364

Westheide W, Rieger R (1996) Spezielle Zoologie Teil 1: Einzeller und wirbellose Tiere. Spektrum Akademischer Verlag, Heidelberg

Williams ST, Benzie JAH (1993) Genetic consequences of long larval life in the starfish Linckia laevigata (Echinodermata: Asteroidea) on the Great Barrier Reef. Mar Biol 117:71-77

Zar JH (1999) Biostatistical analysis, 4th edn. Prentice-Hall, Englewood Cliffs, NJ

Submitted: May 29, 2009; Accepted: January 27, 2011

Proofs received from author(s): April 17, 2011 